\title{
Have 3D endoscopes succeeded in neurosurgery?
}

\author{
Luigi M. Cavallo • Paolo Cappabianca • Felice Esposito
}

Received: 30 April 2014 / Accepted: 2 May 2014 / Published online: 27 May 2014

(C) Springer-Verlag Wien 2014

In recent years endoscopy has represented a terrific advancement in daily neurosurgical practice all over the world, thanks to the ability of the endoscope itself to allow an intrusive vision of the relevant anatomy with a wide and close-up view of the surgical target structures. This has proved to be very useful and widely used, mainly in the treatment of different pathologic conditions of the cerebral ventricles [4] and in transsphenoidal surgery for pituitary adenomas, and also for nonadenomatous lesions of the sellar and perisellar areas $[3,6$, $12,17,11,8]$.

Nevertheless, current endoscopes provide a bidimensional view, and the image as seen on the monitor is the result of a computer elaboration process. Spatial and depth information loss, however, could be overcome on one hand with the ongoing experience of the surgeon, and on the other by the capability of the human brain to elaborate secondary spatial depth cues, i.e. shadows, lights, and parallax movements $[2$, $13-15]$.

It seems that introduction and evolution of 3D technology in endoscopic surgery $[1,7,9,10,18,19]$ has been identified as a viable solution to overcome some limits of $2 \mathrm{D}$ vision, despite the tremendous improvements brought in by the HD system [16].

We cannot deny or minimize the terrific work made by industries in improving 3D technology that deserve care and time to be realized. In such a way, 3D endoscopes represent an important step forward as compared to previous generations, even if the $3 \mathrm{D}$ images still come from the acquisition of a

L. M. Cavallo $\cdot$ P. Cappabianca

Division of Neurosurgery, Università degli Studi di Napoli Federico II, Naples, Italy

F. Esposito $(\square)$

Department of Neurosciences, Division of Neurosurgery, Università degli Studi di Messina, Via Consolare Valeria 1, 98125 Messina, Italy e-mail: felice.esposito@unime.it single sensor (now offering full HD resolution). Anyway, currently there are still several limitations that would limit $3 \mathrm{D}$ endoscopy taking over the $2 \mathrm{D}$ endoscopes. In fact, 3D technology has been initially introduced in laparoscopic surgery, where it is possible to use cameras, lenses, and instruments of bigger sizes, thus allowing production of better images when compared with neurosurgery. Despite such potential advantages, 3D laparoscopy still remains secondary, suggesting that it is not a matter of size but rather of the technology of the 3D image production and perception. So, even though there are recent contributions that shed light on the benefits of 3D endoscopic technology, a massive shift to the use of 3D has not been observed; rather, it has been advocated as an adjunct to the conventional 2D endoscopic technology. Furthermore, this happened only in selected centers, either because of the higher costs of the 3D technology or the difficulties in adapting to the tridimensional vision using goggles.

This condition mostly resembles what is happening in the cinematographic and videogame industries. Many of us have been observing early 3D movies, mainly cartoons, and were definitely fascinated by them. Though, backing upon innovation success, production industries are making conspicuous financial and technical efforts to create $3 \mathrm{D}$ movies, and also to re-master classic blockbusters with this technology. However, it seems that not every movie could take advantage of the $3 \mathrm{D}$ technology rendering, and above all, too many people still complain of difficulties in adapting to this kind of vision, such as headache, nausea, dizziness, and myodesopsis. So recently, the same industries made up their mind and established a new trend with the creation of two versions of the same product, i.e., a 3D HD one and a conventional HD one. The videogames also adopted the same strategy: for instance, the Nintendo 3DS ${ }^{\circledR}$ — latest generation of portable consoles - has been the first to realize a 3D view effect without goggles, but it allows the player to immediately and effectively shift between 
2D and 3D. The choice of vision is highly demanded in players' adaptability and game features, allowing a double option.

A similar strategy has been adopted to develop some 3D endoscopes: a conventional endoscope can be connected to an HD camera, but bigger than its previous version, thus providing the opportunity to switch easily between 2D and 3D view.

Besides 3D - still burdened by the need of goggles - we should mention the development of Ultra-HD technology systems (UHD), which can offer images with resolution up to 7680 pixels wide by 4320 pixels tall (33.2 megapixels), which contain sixteen times more pixels than current Full HD.

In the last decade technological progress has led to tremendous improvements in terms of image quality, but a similar boost in terms of miniaturization of camera-endoscope coupled devices did not happen, at least in neurosurgery. We hope that in the next steps of this evolutionary process, reduction of sizes could be accomplished, and the endoscopecamera coupled device could be easily maneuvered by the surgeon as any other microsurgical instrument (2D or 3D).

It cannot be overstated that ultimately $3 \mathrm{D}$ endoscopy will gain more room in surgery and will finally succeed, and we do not see any reason to stay or to resist this progress. In order to achieve such attitudes as we did in the controversy between endoscopic endonasal versus transcranial surgery [5], we advise the same attitude in defining the role of technology in the present and future assessment of endoscopes in neuroendoscopy. No doubt 3D will contribute to significant improvements that are and will also be coming from 3D not associated with a single sensor, as well as with ultra HD vision and miniaturization.

\section{Conflicts of interest None.}

\section{References}

1. Barkhoudarian G, Del Carmen Becerra Romero A, Laws ER (2013) Evaluation of the 3-dimensional endoscope in transsphenoidal surgery. Neurosurgery 73:ons74-ons 78, discussion ons 78-79

2. Brigner WL, Deni JR, Hildreth LL (1994) Simultaneous changes in length and direction as a cue for perceived depth. Percept Mot Skills 78:1385-1386
3. Cappabianca P, Cavallo LM, Esposito F, De Divitiis O, Messina A, De Divitiis E (2008) Extended endoscopic endonasal approach to the midline skull base: the evolving role of transsphenoidal surgery. Adv Tech Stand Neurosurg 33:151-199

4. Cappabianca P, Cinalli G, Gangemi M, Brunori A, Cavallo L, de Divitiis E, Decq P, Delitala A, Di Rocco F, Frazee J, Godano U, Grothenuis A, Longatti P, Mascari C, Nishihara T, Oi S, Rekate H, Schroeder H, Souweidane M, Spennato P, Tamburrini G, Teo C, Warf B, Zymberg S (2008) Application of neuroendoscopy to intraventricular lesions. Neurosurgery 62:SHC575-SHC598

5. Cappabianca P, Kelly DF, Laws ER Jr (2008) Endoscopic transnasal versus open transcranial cranial base surgery: the need for a serene assessment. Neurosurgery 63:240-241, discussion 241-243

6. de Divitiis E, Cappabianca P, Cavallo LM (2002) Endoscopic transsphenoidal approach: adaptability of the procedure to different sellar lesions. Neurosurgery 51:699-705, discussion 705-697

7. Fraser JF, Allen B, Anand VK, Schwartz TH (2009) Threedimensional neurostereoendoscopy: subjective and objective comparison to 2D. Minim Invasive Neurosurg 52:25-31

8. Jane JA Jr, Han J, Prevedello DM, Jagannathan J, Dumont AS, Laws ER Jr (2005) Perspectives on endoscopic transsphenoidal surgery. Neurosurg Focus 19:E2

9. Kaltenbach T, Leung C, Wu K, Yan K, Friedland S, Soetikno R (2011) Use of the colonoscope training model with the colonoscope 3D imaging probe improved trainee colonoscopy performance: a pilot study. Dig Dis Sci 56:1496-1502

10. Kari E, Oyesiku NM, Dadashev V, Wise SK (2012) Comparison of traditional 2-dimensional endoscopic pituitary surgery with new 3dimensional endoscopic technology: intraoperative and early postoperative factors. Int Forum Allergy Rhinol 2:2-8

11. Kassam A, Snyderman CH, Mintz A, Gardner P, Carrau RL (2005) Expanded endonasal approach: the rostrocaudal axis. Part II. Posterior clinoids to the foramen magnum. Neurosurg Focus 19:E4

12. Laufer I, Anand VK, Schwartz TH (2007) Endoscopic, endonasal extended transsphenoidal, transplanum transtuberculum approach for resection of suprasellar lesions. J Neurosurg 106:400-406

13. Mather G, Smith DR (2000) Depth cue integration: stereopsis and image blur. Vis Res 40:3501-3506

14. O'Shea RP, Blackburn SG, Ono H (1994) Contrast as a depth cue. Vis Res 34:1595-1604

15. Rogers B (2009) Motion parallax as an independent cue for depth perception: a retrospective. Perception 38:907-911

16. Schroeder HW, Nehlsen M (2009) Value of high-definition imaging in neuroendoscopy. Neurosurg Rev 32:303-308, discussion 308

17. Starke RM, Reames DL, Chen CJ, Laws ER, Jane JA Jr (2013) Endoscopic transsphenoidal surgery for cushing disease: techniques, outcomes, and predictors of remission. Neurosurgery 72:240-247, discussion 247

18. Voorhorst FA, Overbeeke KJ, Smets GJ (1996) Using movement parallax for 3D laparoscopy. Med Prog Technol 21:211-218

19. Votanopoulos K, Brunicardi FC, Thornby J, Bellows CF (2008) Impact of three-dimensional vision in laparoscopic training. World J Surg 32:110-118 